Accident Probabilities and Seat Belt Usage:

A Psychological Perspective

P. Slovic, B. Fischhoff and S. Lichtenstein Decision Research

A Branch of Perceptronics

Eugene, Oregon

97401

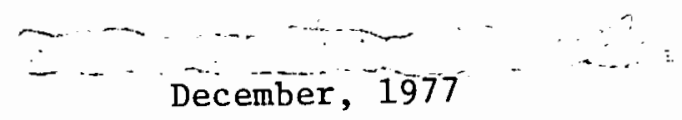

Accident Analysis and Prevention, in press 


\title{
Accident Probabilities and Seat Belt Usage: \\ A Psychological Perspective
}

P. Slovic, B. Fischhoff and S. Lichtenstein

Decision Research

A Branch of Perceptronics

Eugene, Oregon

\begin{abstract}
Motorists' reluctance to wear seat belts is examined in light of research showing (a) that protective behavior is influenced more by the probability of a hazard than by the magnitude of its consequences and (b) that people are not inclined to protect themselves voluntarily against very low probability threats. It is argued that the probability of death or injury on any single auto trip may be too low to incite a motorist's concern. Maintenance of a "single trip" perspective makes it unlikely that seat bêlts will be used. Change of perspective, towards consideration of the risks faced during a lifetime of driving, may increase the perceived probabilities of injury and death and, therefore, induce more people to wear seat belts.
\end{abstract}


Accident Probabilities and Seat Belt Usage:

A Psychological Perspective

P. Slovic, B. Fischhoff and S. Lichtenstein

Decision Research, A Branch of Perceptronics

Eugene, Oregon $97401 \%$

Research has demonstrated that seat belts effectively reduce

injury and death in automobile accidents [Campbell, O'Neill \& Tingley, 1974; Fhanér \& Hane, 1973; Green, 1976; Hodson-Walker, 1970; Preston

\& Shortridge, 1973] and that most people are aware of this fact [Knapper, Cropley \& Moore, 1976; Marzoni, 1971]. It is, therefōre; perplexing that only a small percentage of motorists wear lap belts or shoulder harnesses. Forgetfulness, laziness, inconvenience, discomfort and low perceived risk are reasons given for not wearing belts [Knapper, et al., 1976; Fhanér \& Hane, 1973]. Numerous media campaigns, employing the full armamentarium of "Madison Avenue," have failed to persuade people to "buckle up for safety" [Rober $\div$ son, 1976].

Recently, psychologists have begun to study how people react to low-probability, high-consequence threats. Some of these results suggest reasons why motorists refuse to use seat belts voluntarily. These results and their implications are discussed below.

"This study was supported by the National Science Foundation under Grant No. ENV77-15332 to Perceptronics, Inc. Any opinions, findings, and conclusions or recommendations expressed in this publication are those of the authors and do not necessarily reflect the views of the National Science Foundation. We are indebted to Ward Edwards for his comments on an earlier draft of this paper. 
Psychological Considerations

Over the years, as the number of vehicle miles driven per year in the U.S. has increased, the death rate per $10^{8}$ vehicle miles has steadily decreased, reaching a low of 3.31 in 1976 [Accident Facts, National Safety Council, 1977]. We estimate that approximately 1 in every 3.5 million person trips ends in a fatal accident, and about 1 in every 100,000 person trips results in a disabling injury. ${ }^{\dagger}$ Thus, the probability of death or injury on any given trip is extremëly low. Considered in the light of basic principlès of learning and cognition, these probabilities make it unreasonable to expect people to use seat belts voluntarily. Figure 1 presents the rationale behind this assertion schematically.

Attitudes and behaviors reflect people's experience. In particular, it has long been known [e.g., Thorndike, 1913] that rewarded actions tend to be repeated while, nonrewarded behavior diminishes in frequency. Fortunately, the overwhelming majority of driving experiences are accident free. Each safe trip rewards (reinforces) the non-use of seat belts: the expense of buckling up has been saved without incurring any cost. On the other hand, travelers who do use belts are punished (negatively reinforcèd) by the effort, inconvenience, and discomfort they have incurred without any - cóncrete reward. Peace of mind, usually considered the immediate tangible reward for insuring oneself, may seem a pale compensation and one that

†Our calculations of injury and fatality probabilities are based upon the 1969 Nationwide Personal Transportation Study [U.S. Dept. of Transportation], which estimated the total annual number of person trips in passenger cars and trucks at $163,282,000,000$. Traffic fatality rates used here exclude fatalities involving pedestrians or pedal cycles. The probability of a disabling injury (disabling beyond the day of the accident) is estimated as about 40 times higher than fatality probability, based on data presented in Accident Facts. [National Safety Council, 1977]. 


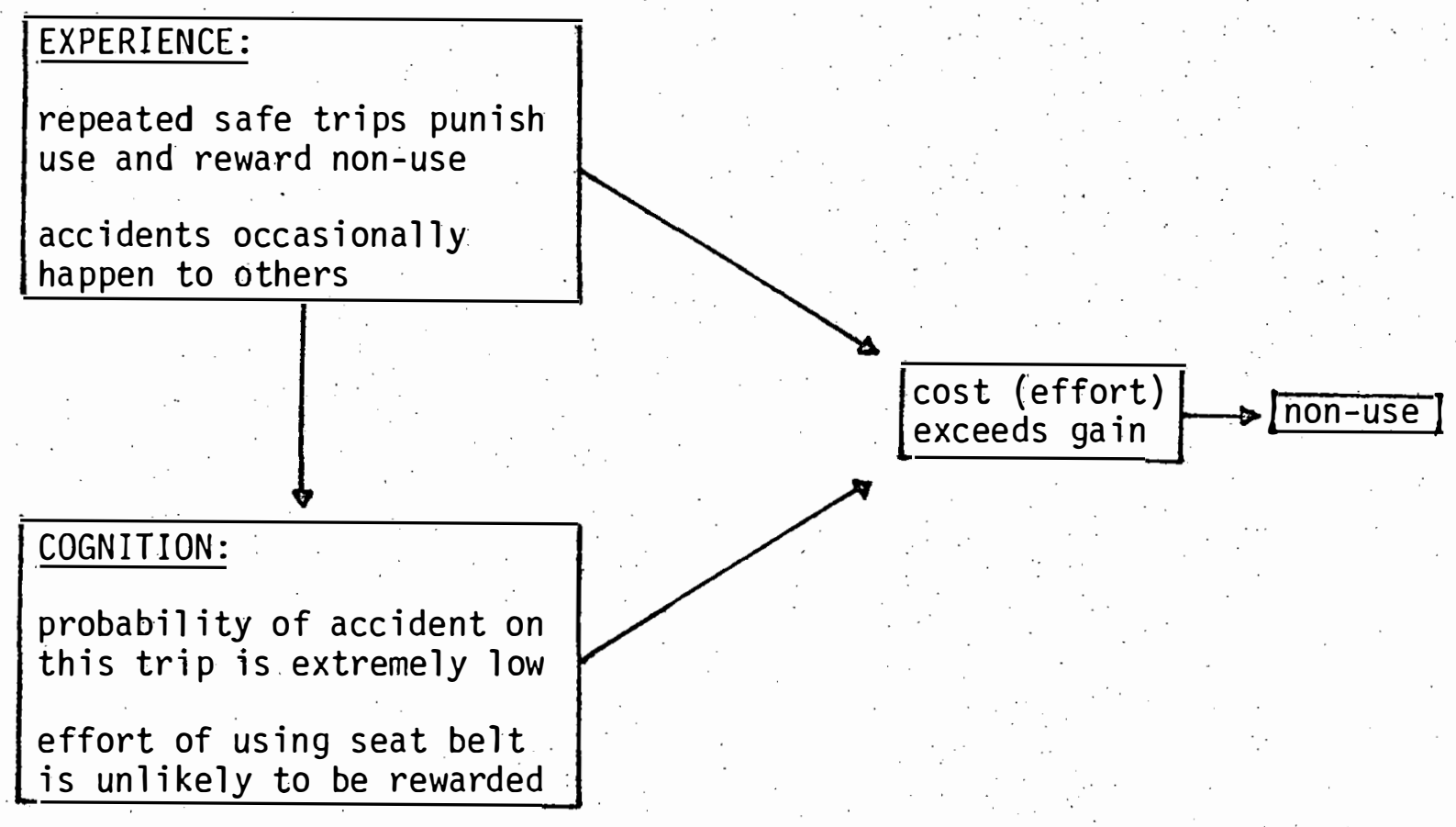

Figure 1. Psychological Considerations in the Non-Use of Seat Belts 
is" hard to enjoy while driving. Thus, safe driving experiencesscan $r$ be expected to lead to non-use of seat belts.

Insert Figure 1 about here

other factors may further reduce people's belief in the efficacy of buckling up: (a) the knowledge that seat belts are not $100 \%$ effective [Fhanér \& Hane, 1974]; (b) drivers' tendencies to view vehicle risks as under their control [Fischhoff, Slovic, Lichtenstein, Read and Combs, in press], coupled with the fact that perceived control produces exaggerated feelings of confidence [Langer, 1975]; and (c) the fact that $75 \%$ to $90 \%$ of the drivers in various countries consider themselves to 1. be better than average [Svenson, 1977]. We do occastonally see or read about accidents, but the victims are other people.

The failure to use seat belts surprises us because of the extremely high value people pläce on theirr lives. Even a very small probability of saving one's life or avoiding serious injury should make the expected gain from using a seat belt exceed the costs. Such reasoning assumes that people have the :unlimited time, energy and attentional capacities needed to have an infinite reservoir of concern. In fact, however, there are only so many things people can worry about and protect themselves against. Unless many hazards are ignored, obsessive preoccupation with risk would preclude any sort of productive life.

When choosing which life-threatening events to ignore, those with probabilities near zero are obvious"candidates. Indeed, there are many threats, that we routinely ignore in order to go on with the business of living: elevators falling, dams bursting, televisions exploding, etc. 
For many people, auto accidents may seem so improbable that they fail to incite concern.

Insurance Behavior: Supporting Evidence

An instructive analog to the seat-belt problem can be found in

another type of protective activity: buying insurance. People's

resistance to purchasing insurance is well known. Consider, for example, the following testimony by George Bernstein, then Federal Insurance

Administrator, before a U.S. Senate subcommittee:

- . most property owners -simply do not buy insurance

voluntarily, regardless of the amount of equity they have at

stake. It was not until banks and other lending institutions

united in requiring fire insurance from their mortgagers that

most people got around to purchasing. it . . and we just need

look at our automobile :insurance laws to recognize that unless

we force that insurance down the throats of the drivers, many,

many thousands of people would be unprotected on the highways.

People do not buy insurance voluntarily unless there is

pressure on them from one source or another [Bernstein, 197.2; p. 23:].

Efforts by the government and private companies to induce people

to insure their property against earthquakes and flood damage have

been spectacularly unsuccessful [Anderson, 1974], much like the seat-

belt campaigns. Even strong economic incentives, such as $90 \%$ premium

subsidiès; : have not stimulated flood insurance sales.

There are, of course, some unlikely hazards to which people react quite strongly, nuclear reactor accidents being a prime example. We believe this reaction occurs because critics perceive the probability of a catastrophic accident to be quite high. People have no firsthand experience with (the safety of) nuclear power; instead, they mưst rely on the news=nedia which typically pay more attention to breakdowns and potentiai accidents than to the successful day-to-day operations of power plants. 
Concern about the viability of insurance as a mechanism for coping with risks from natural hazards has led to several recent field surveys and laboratory studies of insurance decision making [Kunreuther, Ginsberg, Miller, Sagi, Slovic, Borkin \& Katz, 1978; Schoemaker, 1977; Slovic, Fischhoff, Lichtenstein, Corrigan \& Combs, 1977]. One robust finding from this research has been that people are more willing to insure against small losses with relatively high probabilities than against large but unlikety losses. Table 1 illustrates this effect with data from an experiment performed by Slovic, et al. [1977] in which people played an elaborate farm management game. One of their many decisions was whether or not to insure against each of five natural hazards. The probability of occurrence of these hazards ranged from .002 to .25. The magnitude of loss varied inversely with the probability of occurrence such that the expected loss (i.e., probability multiplied by loss) was the same for each. Premiums were set slightly above the expected loss. As the table shows, people were much more likely to insure against relatively high-probability, low-loss hazards than against low-probability, high-loss hazards. This behavior, which has also been obtained in other experiments, runs counter to that postulated by the traditional economic theories of insurance [e.g., Friedman \& Savage, 1948]. Those theories assume that people wish to protect themselves against rare, catastrophic losses that they could not bear themselves. Outside the laboratory, the popularity of low-deductible insurance plans +[Fuchs, 1976; Pashigian, Schkade \& Menëfee, 1966] which offer expensive coverage for sma11, but likely, losses is consistent with results from the experiments. 
Table 1

Effect of Probability of Loss on Insurance Purchase Decisions in a Farm Management Game ${ }^{a}$

\begin{tabular}{cccc}
$\begin{array}{l}\text { Probability } \\
\text { of Loss }\end{array}$ & $\begin{array}{c}\text { Magnitude } \\
\text { of Loss }\end{array}$ & $\begin{array}{c}\text { Insurance } \\
\text { Premium }\end{array}$ & $\begin{array}{l}\text { Percent of } \\
\text { Persons Insuring }\end{array}$ \\
.002 & $\$ 247,500^{b}$ & $\$ 500$ & 33 \\
.01 & 49,500 & 500 & 45 \\
.05 & 9,900 & 500 & 52 \\
.10 & 4,950 & 500 & 49 \\
.25 & 1,980 & 500 & 73 \\
\hline
\end{tabular}

a Taken from Slovic, Fischhoff, 'Lichtenstein, Corrigan \& Combs, 1977.

$\mathrm{b}_{\mathrm{A}}$ loss of this magnitude would cost the individual the farm. 
Two considerations seem to dominate these insurance decisions, both inside and outside the laboratory. One is the disinclination to worry about (1ow-probability insurance as an investment. Insuring against probable losses increases the probability of making a claim and getting something tangible for one's premium dollars.

\section{Implications}

Given these results, we might expect that many motorists would find it irrational to bear the costs (however slight) of buckling up in return for partial protection against an overwhelmingly unlikely accident. On the other hand, public safety officials, who must consider an entire population of drivers taking many trips, view the problem quite differently. Whereas the probability of seat belt usage being beneficial on any one trip is miniscule, any increment in the percentage of trips on which seat belts are worn is certain to save many lives and prevent many injuries. Such differing perspectives may trigger much of the conflict and mutual frustration between public officials and motorists, each believing (with some justice) that their analysis of the situation is correct.

It followis from the psychological considerations described above that appeals based on either the efficacy of seat belts (in the event of an accident) or lurid descriptions of accidents will be ineffective unless they somehow raise the perceived probability of accidents. Indeed, such appeals have not worked in practice [e.g., Robertson, Kelley, O'Neill, Wixom, Elswirth \& Haddon, 1974]. As long as accidents are viewed as .- 
virtually impossible, efficacy and damage mean little. In his review of fifteen years of research on fear arousal and the failure of threat appeals, Higbee [1969] reached a similar conclusion. He noted:

"The severity of the consequences (threat level) and the probability of their occurrence may be negatively related. Thus, a highly threatening consequence (e.g., paralysis or blindness) may not be seen as too likely to result from not brushing one's teeth, whereas it may be seen as more likely that not brushing one's teeth could lead to cavities. If such a negative relationship exists, then increases in fear level could lead to decreases in perceived probability of occurrence of the threat and thus to decreased persuasiveness" [p. 440].

Our analysis suggests that voluntary use of seat belts depends on motorists believing that their personal likelihood of being in an accident is high enough to make wearing a belt sensible. As long as the chances of accident on any given trip remain miniscule, the only hope may be to get people to think about"the risks faced over a lifetime of driving. $\quad$ The 1969 Nationwide Personal Transportation Study indicates that the average U.S. citizen makes about 800 automobile trips per year. This suggests that the probability of a fatal accident sometime within a fifty year period of driving (40,000 trips) is about .01, while the probability of experiencing at least one disabling injury is about .33. ' Perhaps presentation of these probabilities, along with the

TThese probabilities were based on assumed rates of one fatality per 3.5 million trips and one disabling injury per 100,000 trips combined with the assumption that these events are randomly and independently distributed. Given these assumptions, the probability of experiencing a fatality in 40,000 trips is $1-[1-1 / 3,500,000]^{40,000}$ and the probability of experiencing one or more disabling accidents in 40,000 trips is $1-[1-1 / 100,000]^{40,000}$. 
admonition that "no one knows when that accident will come," might trigger concern and increase the use of seat belts.

In our laboratory experiments, we found that people could be induced to purchase insurance against rare threats by lengthening thèir time perspective.[Slovic et ä1., 1977]. Supporting evidence more germane to seat belts comes from an exploratory study we recently conducted. The participants in this study were 38 men and 41 women who responded to an advertisement placed in the University of Oregon newspaper. Most were students; their range of ages was 17-50 years, with a median of 21 years. Participants were assigned randomly to one of two groups. One group was given the probabilities of death and injury per single trip along with the following statement:

"Because the probability that any particular automobile trip willend in death or serious injury is so very sma11, the wearing of seat belts is just not necessary. Any effort or inconvenience involved in wearing seat belts, however slight, is unlikely to be repaid."

The second group was given the probabilities of death and injury in the course of 40,000 trips. They were then told:

"Because these probabilities of death or serious injury are so high, the wearing of seat belts is quite important. Any effort or inconvenience involved in wearing seat belts is likely to be repaid."

After being exposed to the single trip or lifet 1 me $(\pi 0,000$ trips $)$ statistics and the statements that accompanied them, both groups were asked several questions about the likely impact of this information on their use of seat belts and their attitude towards enactment of laws requiring 
the use of some sort of protection, either wearing of seat belts or installation of air bags.

Prior to presenting any information about accident probabilities, we examined our participants' opinions about the effectiveness of seat belts. We also asked them to indicate the frequency with which they wore seat belts. There were no differences between the two groups on either of these measures. However, differences between groups did appear after the statistics were presented. Few respondents 44 out of 41) believed their use of seat belts would be changed as a result of exposure to the single-trip statistics, but $39 \%$ of those exposed to the lifetime: probabilities said they expected their use of seat belts to increase because of this information. Whereas $54 \%$ of the persons who received single-trip information favored mandatory protection, $78 \%$ of those exposed to lifetime statistics favored such a law. Participants in both groups were later shown both single-trip and lifetime information accompanied by the respective anti- and pro-seat belt statements. When asked to compare the statements and indicate which was more convincing, $80 \%$ of the participants selected the pro-seat belt argument based on the probabilities over the course of 40,000 trips.

While this study is promising, we have no assurance that the favorable attitudes towards seat belts engendered by a lengthened time perspective will be maintained and translated into behavior, especially in light of people's repeated safe experiences with automobile trips. If a favorable perspective cannot be maintained, public safety officials will have to reassess the problem. Strictly enforced 


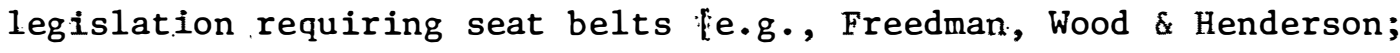
1974] or passive devices such as air bags may be the only way to ensure that the majority of motorists are adequately protected.

\section{Conclusion}

The small probability of accidents, continually reinforced by safe experifences, in conjunction with people's limited capability to attend to rare threats, helps explain the non-use of seat belts. While this perspective on the problëm indicates one approach towards increasing voluntary use of seat belts, it also suggests that there is an element of rationality in people's behavior that may keep voluntary use at its current low rate. 


\section{References}

Anderson, D. R. The national flood insurance program--problems and potentia1. Journal of Risk and Insurance, 41, 579-599, 1974.

Bernstein, G. K. Testimony before the U.S. Senate Subcomittee on Housing and Urban Affairs, 92nd Congress, S.2794 - A Bill to Amend the National Flood Insurance Act of 1968 to Increase Flood Insurance Coverage of Certain Properties; to Authorize the Acquisition of Certain Properties, and for other Purposes (Washington, D. C.: U. S. Government Printing Office), p. 23, 1972 .

Campbell, B. J., O'Neill, B. and Tingley, B. Comparative injuries to. belted and unbelted drivers of sub-compact, compact, intermediate and standard cars. University of North Carolina Highway Safety Research Center, Chapel Hill, N. C., 1974.

Fhanér, G. and Hane, M. Seat belts: Factors influencing their use.

A literature survey. Accident Analysis and Prevention, 5, 27-43, 1973.

Fhanér, G. and Háne, M. Seat belts: Relations between beliefs, attitudes and use. Journal of Applied: Psychology, 59, 472-482, 1974.

Fischhoff, B., Slovic, P., Lichtenstein, S., Read, S. and Combs, B. How safe is safe enough? A psychometric study of attitudes towards technological risks and benefits. Policy Sciences, in press.

Freedman, K., Wood, R. and Henderson, M. Compulsory seat belts: A

Survey of public reaction and stated usage. Department of Motor Transport, New South Wales, 1974.

Friedman, M. and Savage, L. J. The utility analysis of choices involving risk. Journal of Political Economy, 56, 279-304, 1948.

Fuchs, V. R. From Bismarck to Woodcock:" The "irrational" pursult of nattonal: health insurance.. The Journal of Law and Economics, 19, 347-359, 1976, Green, P. G. Ontario's buckle up law is paying off. Traffic Safety, 76, 8-11 \& 34-35, July, 1976. 
under risk: An information processing approach. Unpublished

Ph.D. Dissertation, Department of Decision Sciences, The Wharton..

Schoo1, University of Pennsylvania, 1977.

$=0=$

Slovic, P., Fischhoff, B., Lichtenstein, S., Corrigan, B. and Combs, B.

Preference for insuring against probable small losses: Implications

for the theory and practice of insurance, Journal of Risk and

Insurance, 44, 237-258, 1977.

Svenson, 0. Risks of road transportation from:a psychological point of

view. Report 3-77 of the Risk. Project, Committee for Future Oriented

Research, Stockholm, Sweden, 1977.

Thorndike, E. L. The psychology of learning. New York: Teachers College, 1913. 